\title{
Implementation of Social Networking Application as a Tool for English Language Learning in Vocational and Boarding School
}

\author{
Eka Widhi Yunarso $^{1}$, Pikir Wisnu Wijayanto ${ }^{1}$, and Ismail ${ }^{2}$
}

\begin{abstract}
SMK Al - Aitaam and PERSIS Boarding School is a place in the field of education, which are based on Islamic education. Development of science, technology, language very rapidly at this time also encourages the two educational institutions to incorporate foreign language learning (English) curriculum or guidelines in the learning process that runs in the two institutions. But learning undertaken encountered several problems such as lack of media dynamic learning English, which is always updated, by the changing times, the lack of computer facilities and internet media that can be used by students to add to the English vocabulary. To overcome it offered a solution to support English language learning by designing learning materials covering a wide range of intergrated skills competency which can be accessed free of charge by the students and teachers in the form of a social networking application that allows students improve their English skills by using a variety of features provided, ranging mastery of reading, writing and listening.
\end{abstract}

Keywords_- English, Social Networking.

\section{INTRODUCTION}

S MK Al - Aitaam and PERSIS Boarding School is a place in the field of education, which are based on Islamic education. Development of science, technology , language very rapidly at this time also encourages the two educational institutions to incorporate foreign language learning (English) curriculum or guidelines in the learning process that runs in the two institutions. But learning undertaken encountered several problems such as lack of media dynamic learning English, which is always updated, by the changing times, the lack of computer facilities and internet media that can be used by students to add to the English vocabulary.

The development of ICT also encourages the emergence of social networking sites that connect users with other users in the form of friendship. Features were given in English, so it requires the user to at least learn the English language. The features of good communication through chat or comments can be used as a medium of teaching and learning English.

The purpose of this research is how to provide a solution to support English language learning by designing learning materials covering a wide range of integrated competency skills (intergrated skills competency) which can be accessed free of charge (free) by the students and teachers in the form of a social networking application which allows the students improve their English skills by using a variety of features provided, ranging mastery of reading [1], writing [2] and listening [3].

\section{A. Literature}

There is some literature that is used in support of this research:

a. English is a foreign language that is taught is considered essential for the purpose of application and development of science, technology, art and

${ }^{1}$ Eka Widhi Yunarso, Pikir Wisnu Wijayanto are with Information System Program, Telkom University, Bandung, Indonesia. E-mail: ekawidhi0622@gmail.com; pww@politekniktelkom.ac.id.

${ }^{2}$ Ismail is with Computer Engineering Program, Telkom University, Bandung, Indonesia. E-mail: ism@politekniktelkom.ac.id. culture, as well as the development of relations between nations [4].

b. The social network is a social structure made up of the nodes (which are generally individuals or organizations) that are tied by one or more specific types of relationships such as values, visions, ideas, friends, offspring etc [5].

c. Data Flow Diagrams (DFD) is a graphical representation of a system that is used to describe the flow and transformation of data that moves from data input to the output. DFD describes the components of a system, the data streams in which these components, and the origin, destination and storage of data [6] [7].

d. ER Diagram is a model to explain the relationship between the data in the database objects based on the data base has relations between relations. ERD is used to model data structures and relationships between data, used to describe some notation and symbols [8].

e. PHP (or official PHP: Hypertext Preposessor) is a server-side script that is added to the HTML. PHP itself is singakatan from Personal Home Page Tools. This script will make an application can be integrated into HTML, so that a web page is no longer static, but a dynamic [8].

\section{METHOD}

Analysis and modeling applications using structured methods, with the DFD as a modeling system and ERD as a database modeling in figure 1 .

\section{RESULT AND DISCUSSION}

\section{A. System Requirements Analysis}

a. Functional Needs Analysis System, there are several functions that must be made, such as: login functionality; registration of new users; functionality exchange of information through the comments; chat functionality between users; English learning and practice, helping a friend in the process of learning and practice (Help Others). 
b. Analysis of users, users who use this application a user's / people who want to improve the ability / skills of the English language. Users here are general users, not limited to age, citizenship, and education.

c. System Overview, to run this application user required to be registered as a member. Where the user is a regular user, who can log in after registration, learn and practice, manage friends, and others listed in the user manual analysis. English learning content to be used is attached in this report.

d. Hardware Requirements, the following are the specifications of the hardware requirements needed in making social networking apps for learning English.

e. Software Requirements, the following are the software requirements specification is required in making social networking apps for learning English.

\section{B. Design}

a. Design ER Diagram, ER Diagram The following is the design of social networking applications for the creation of learning English. In the design of ER diagram below, there are 12 (twelve) entities that chapter, add, ask, chat, comment, complain, do, DO2, learn, message, practice, user.

b. Design of Context Diagram, here is the design of Data Flow Diagrams (DFD) of making social networking apps for learning English. In the design of context diagram below, there are 2 (two) source and / or destination of data (external entities) and 1 (one) main process. Design of DFD Level 1, describes what processes are provided by social networking apps for learning English. In DFD Level 1 , there are 9 (nine) process, 2 (two) entities and 12 (twelve) data store.

\section{Implementation}

On the implementation of social networking applications for learning English, will be used by the two groups, namely administrators and users. As there is a difference and relation can be seen directly from the functions that exist within this application.

Functionality that can be done by the administrators of social networking apps for learning English, among others, managing user data, manage the data of learning and managing user complaints.

Functionality provided in the user accounts including processing messages, manage friends, chat, contribute, learn and practice. Here are some implementations display interface.

Figure 5 is an implementation view veranda on the application of social networking for learning English. The view used by users who want to use social networking applications, beginning with registration to obtain a username and password.

Figure 6 is an implementation of functionality to manage your friends on the social networking application for learning English. By using this functionality, users can make additions or delete friends friendship.

Figure 7 is an implementation of the functionality of learning and practice in the application of social networking for learning English. By using this functionality, users can perform the process of learning English begin mastering reading, writing and listening.

\section{Testing}

a. Functional and system testing using black box testing techniques, testers examine the high-level design and the customer requirements specification to plan the test cases to ensure the code does what it is intended to do. Functional testing involves ensuring that the functionality specified in the requirement specification works. System testing involves putting the new program in many different environments to ensure the program works in typical customer environments with various versions and types of operating systems and/or applications. System testing is testing conducted on a complete, integrated system to evaluate the system compliance with its specified requirements [10].

b. Acceptance testing, After functional and system testing, the product is delivered to a customer and the customer runs black box acceptance tests based on their expectations of the functionality. Acceptance testing is formal testing conducted to determine whether or not a system satisfies its acceptance criteria (the criteria the system must satisfy to be accepted by a customer) and to enable the customer to determine whether or not to accept the system [10]. These tests are often pre-specified by the customer and given to the test team to run before attempting to deliver the product. The customer reserves the right to refuse delivery of the software if the acceptance test cases do not pass. However, customers are not trained software testers. Customers generally do not specify a "complete" set of acceptance test cases. Their test cases are no substitute for creating your own set of functional/system test cases. The customer is probably very good at specifying at most one good test case for each requirement. As you will learn below, many more tests are needed. Whenever possible, we should run customer acceptance test cases ourselves so that we can increase our confidence that they will work at the customer location.

Here is one example of the testing conducted on the application of social networking for learning English, which is contained in Table 3 and Table 4.

\section{CONCLUSION}

The end result of this research is a social networking application for learning English that provide convenience as a medium of communication and sharing among users in improving English language skills, using a variety of features provided, ranging mastery of reading, writing and listening.

\section{REFERENCES}

[1]. J. C. Richards, New Interchange Student's Book 1, New York: Cambridge University Press, 1998.

[2]. J. C. Richards, New Interchange Student's Book 2, New York: Cambridge University Press, 1998.

[3]. J. C. Richards, New Interchange Student's Book 3, New York: Cambridge University Press, 1998.

[4]. Depdikbud, 2011. [Online].

[5]. "Social Networking," 2 March 2011. [Online]. Available: http://id.wikipedia.org/wiki/social_networking..

[6]. T. DeMarco, Structured Analysis and System Specifications, New York: Prentice Hall, 1979. 
[7]. E. Yourdon, Modern Structured Analysis, New Jersey: PrenticeHall International Inc., Englewood Cliffs, 1989.

[8]. Y. Kustiyahningsih, Pemrograman Basis Data Berbasis Web Menggunakan PHP \& MySQL, Yogyakarta: Graha Ilmu, 2011.
[9]. R. S. Pressman, Software Engineering: A Practitioner's Approach, Singapore: McGraw-Hill, 2006.

[10]. IEEE, "IEEE Standard Glossary of Software Engineering Terminology," in IEEE Standard 610.12-1990, 1990.

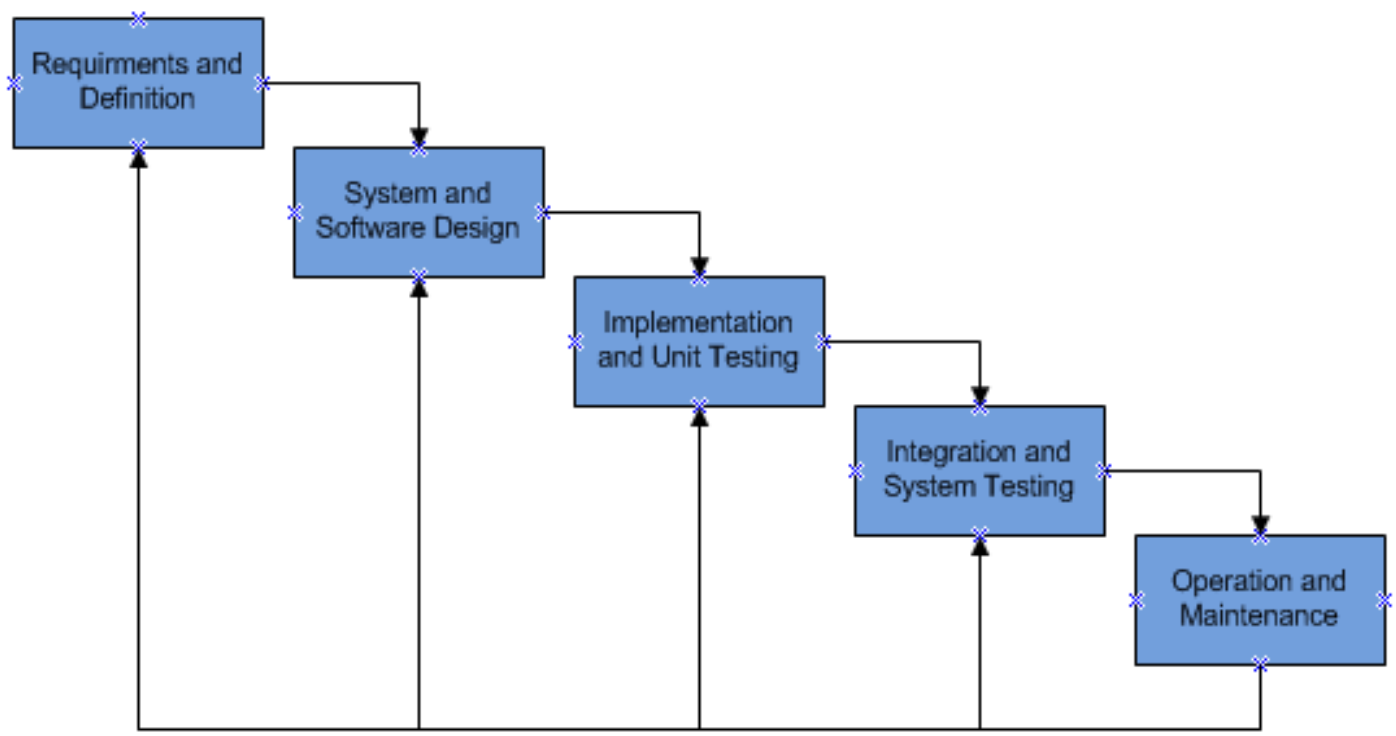

Figure 1. Waterfall Model [9]

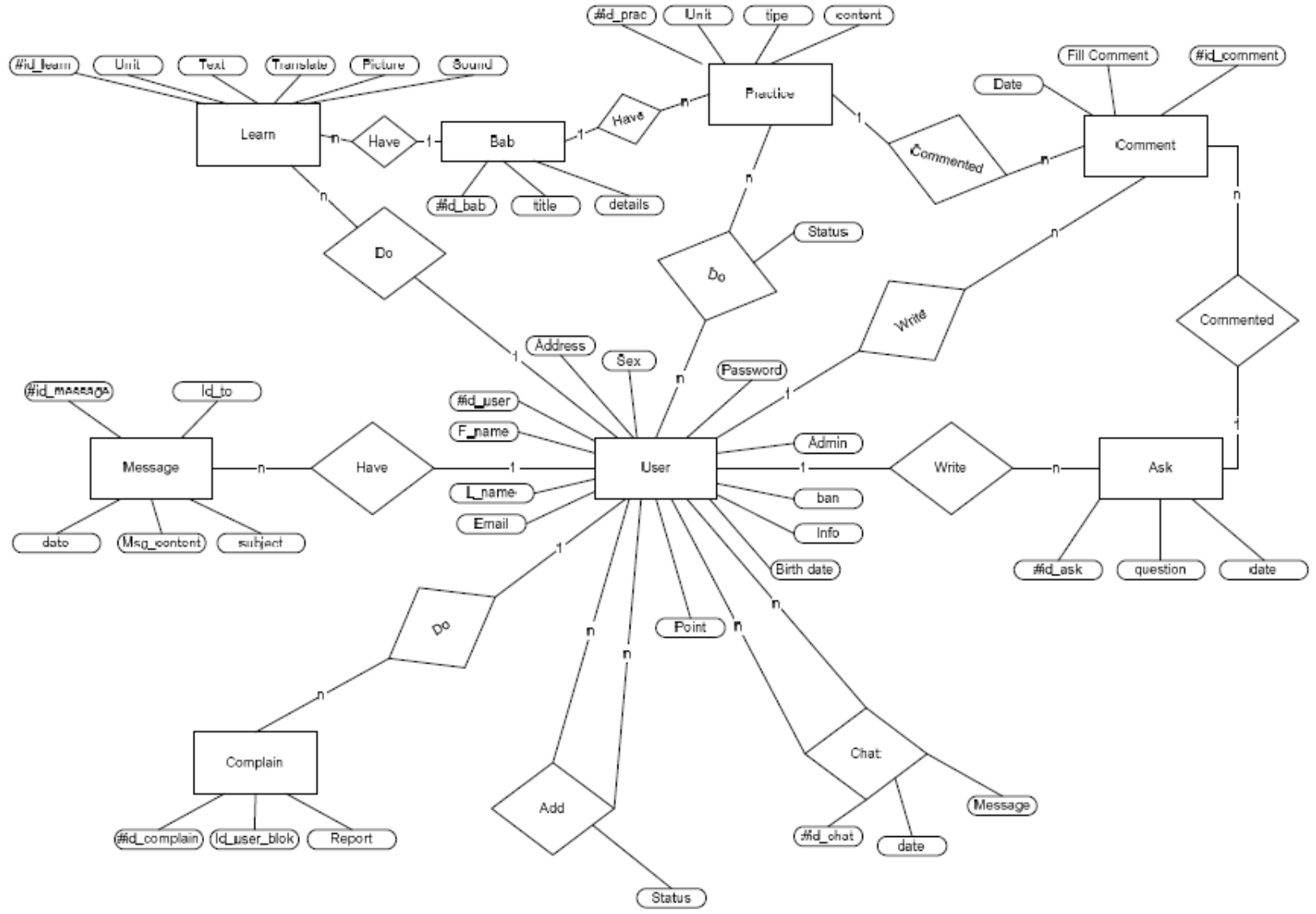

Figure 2. ER Diagram of Social Networking Application 


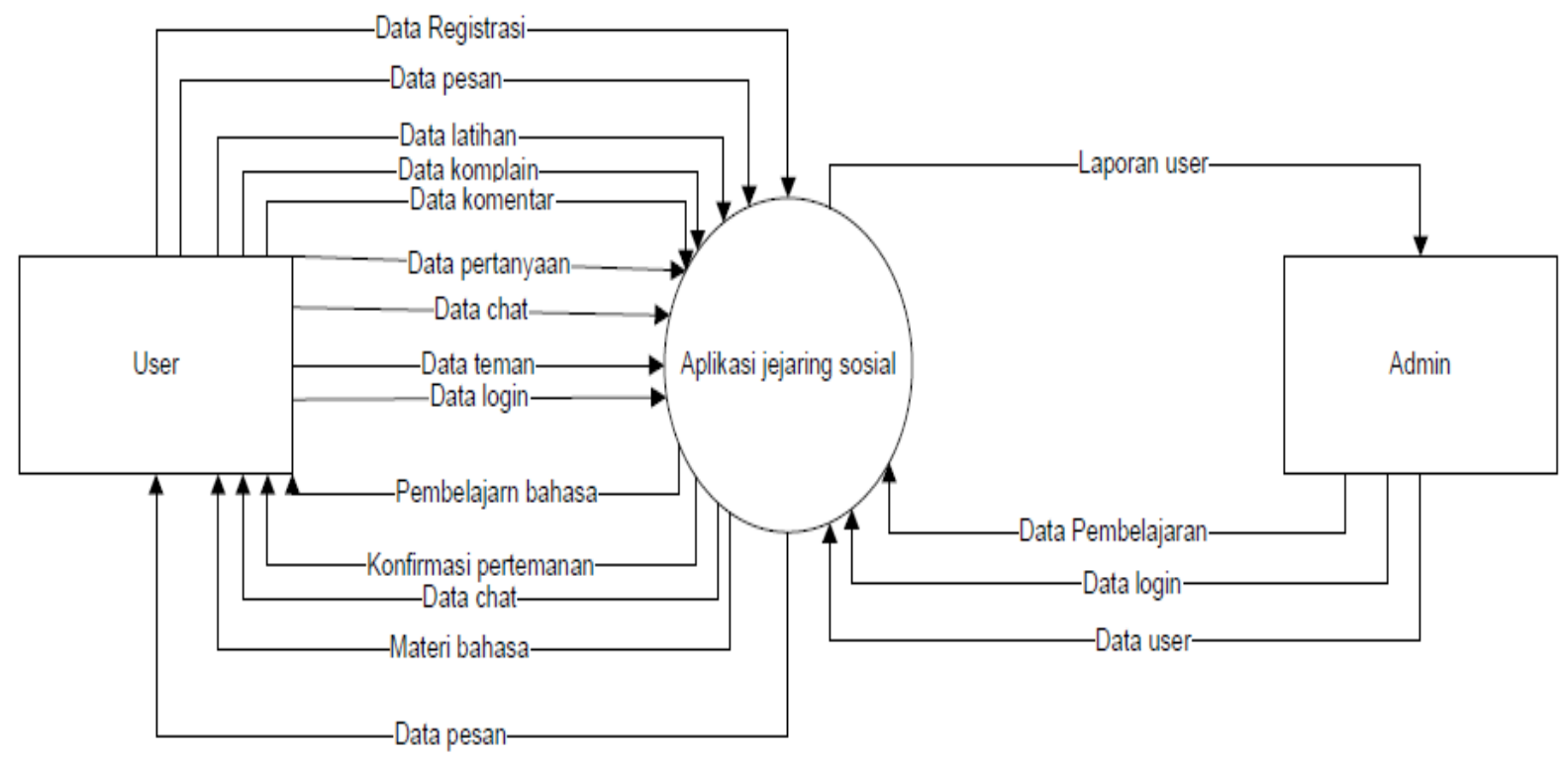

Figure 3. Context Diagram of Social Networking Application

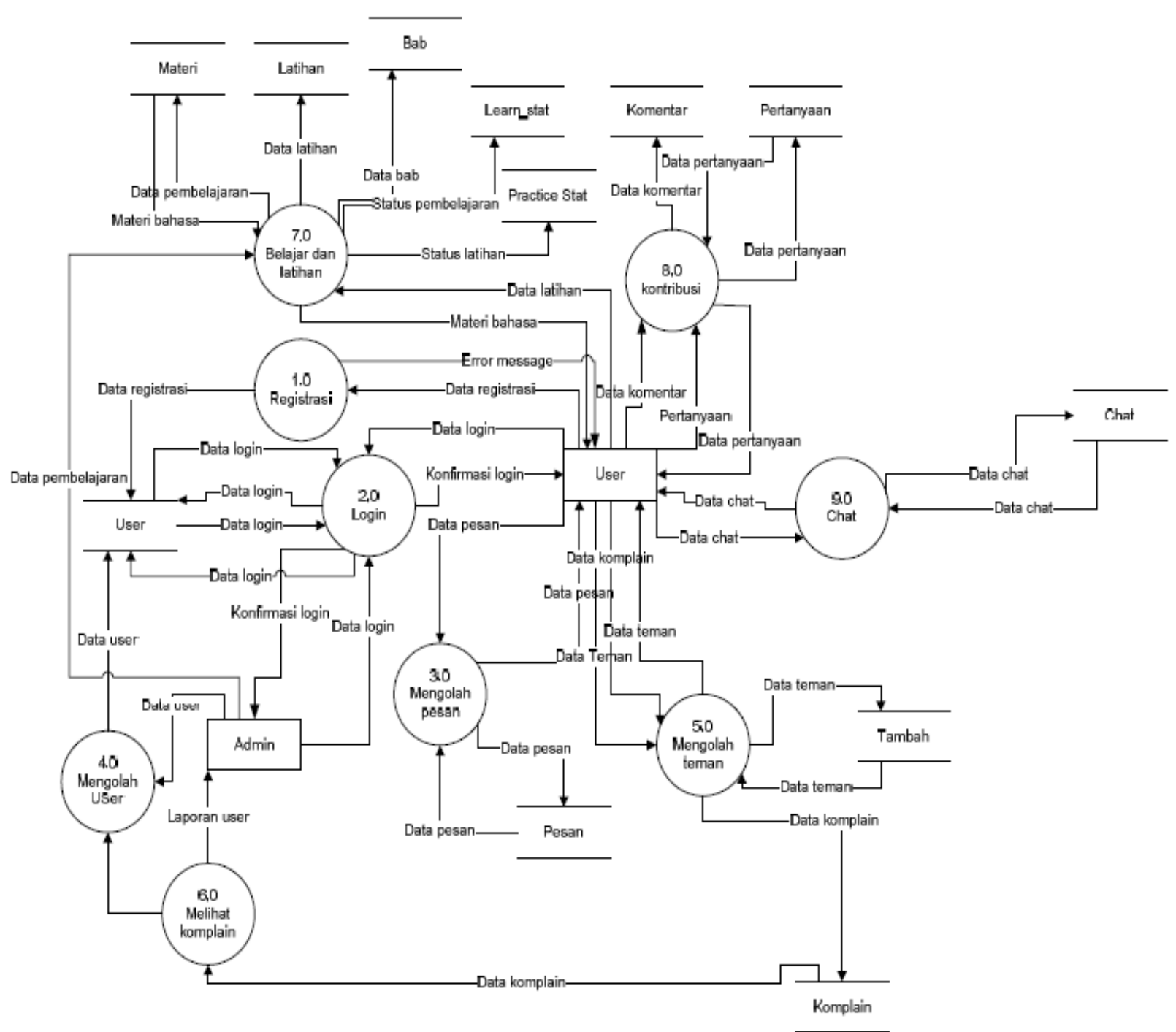

Figure 4. 1st DFD’s Level of Social Networking Application 


\section{Email} Passmord
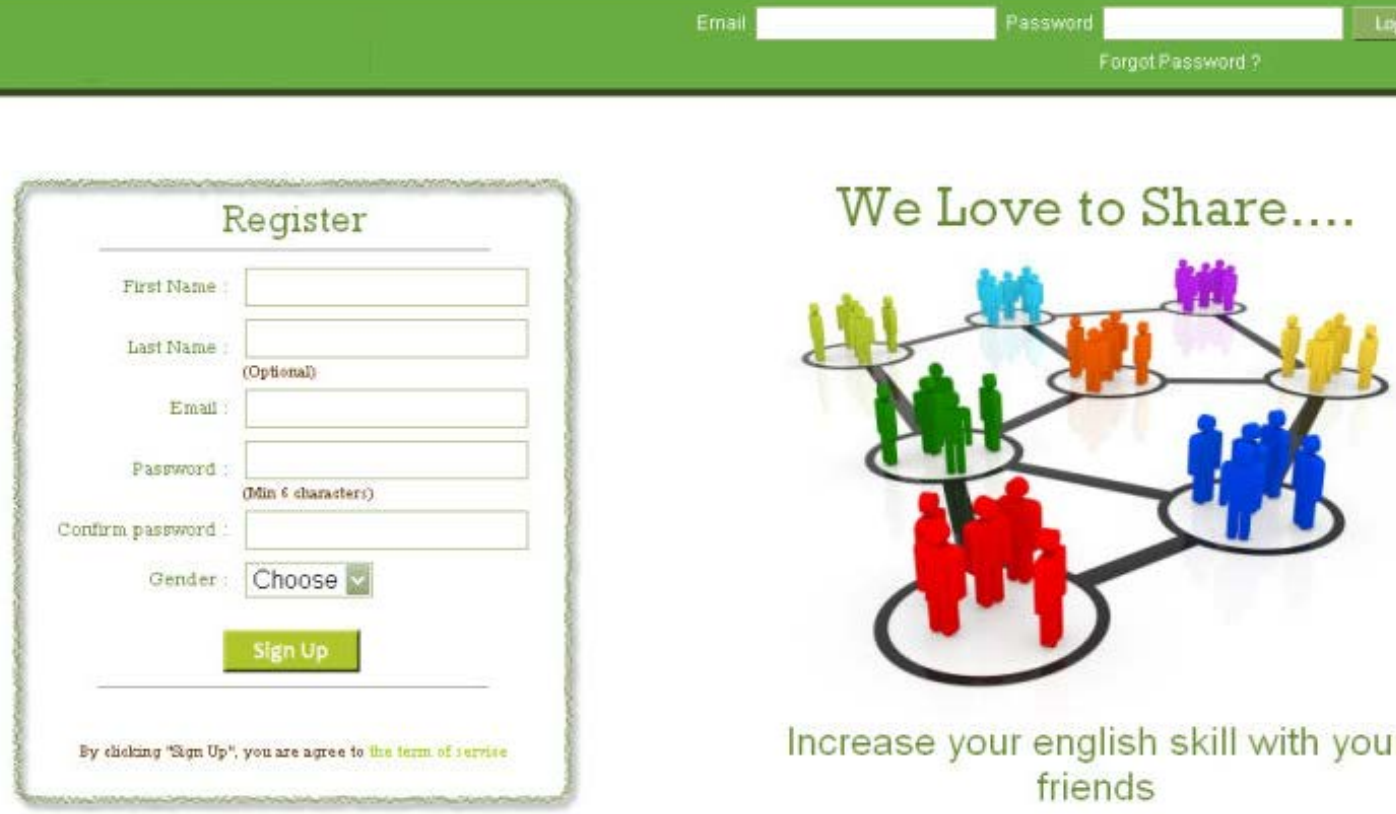

Increase your english skill with your friends

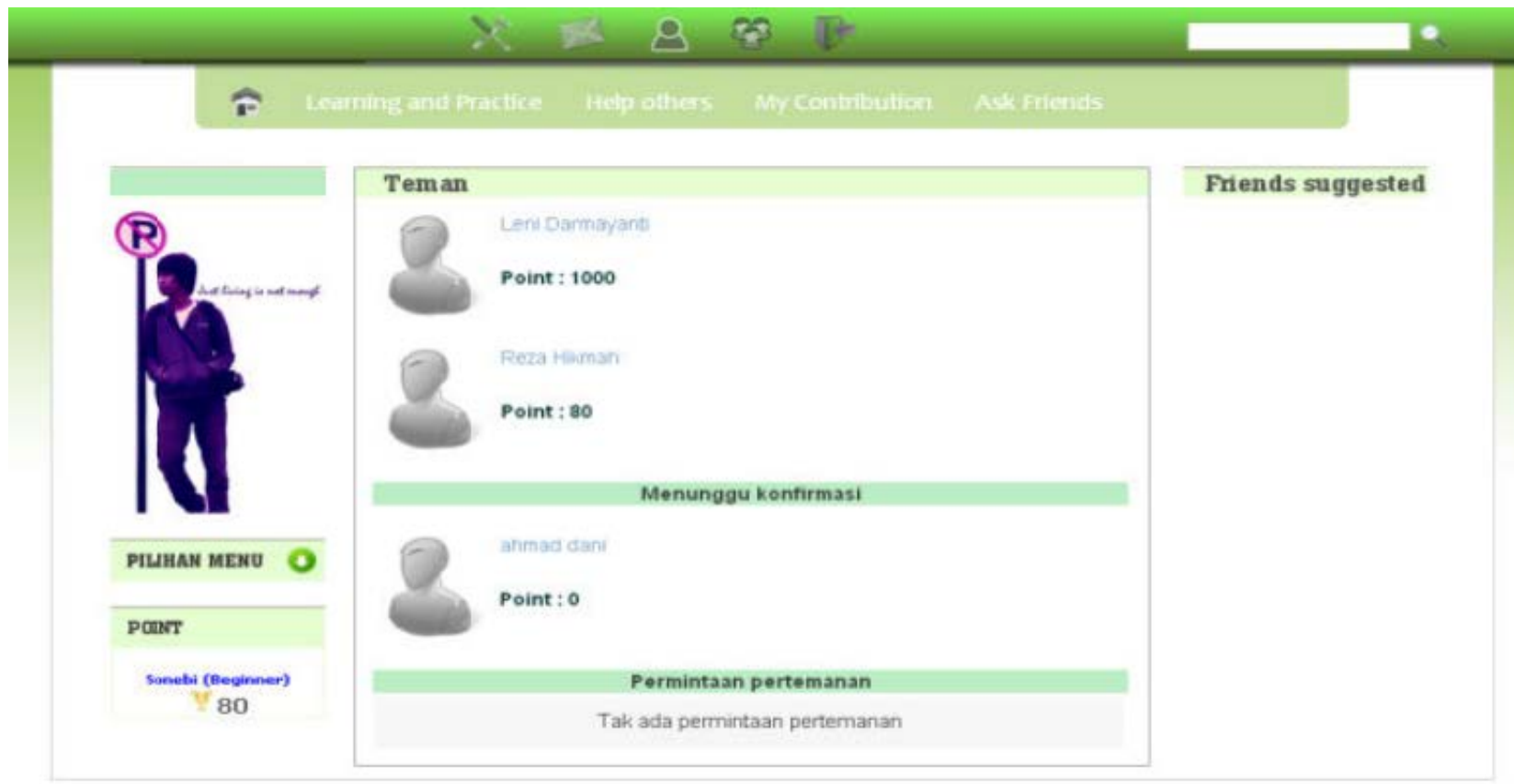




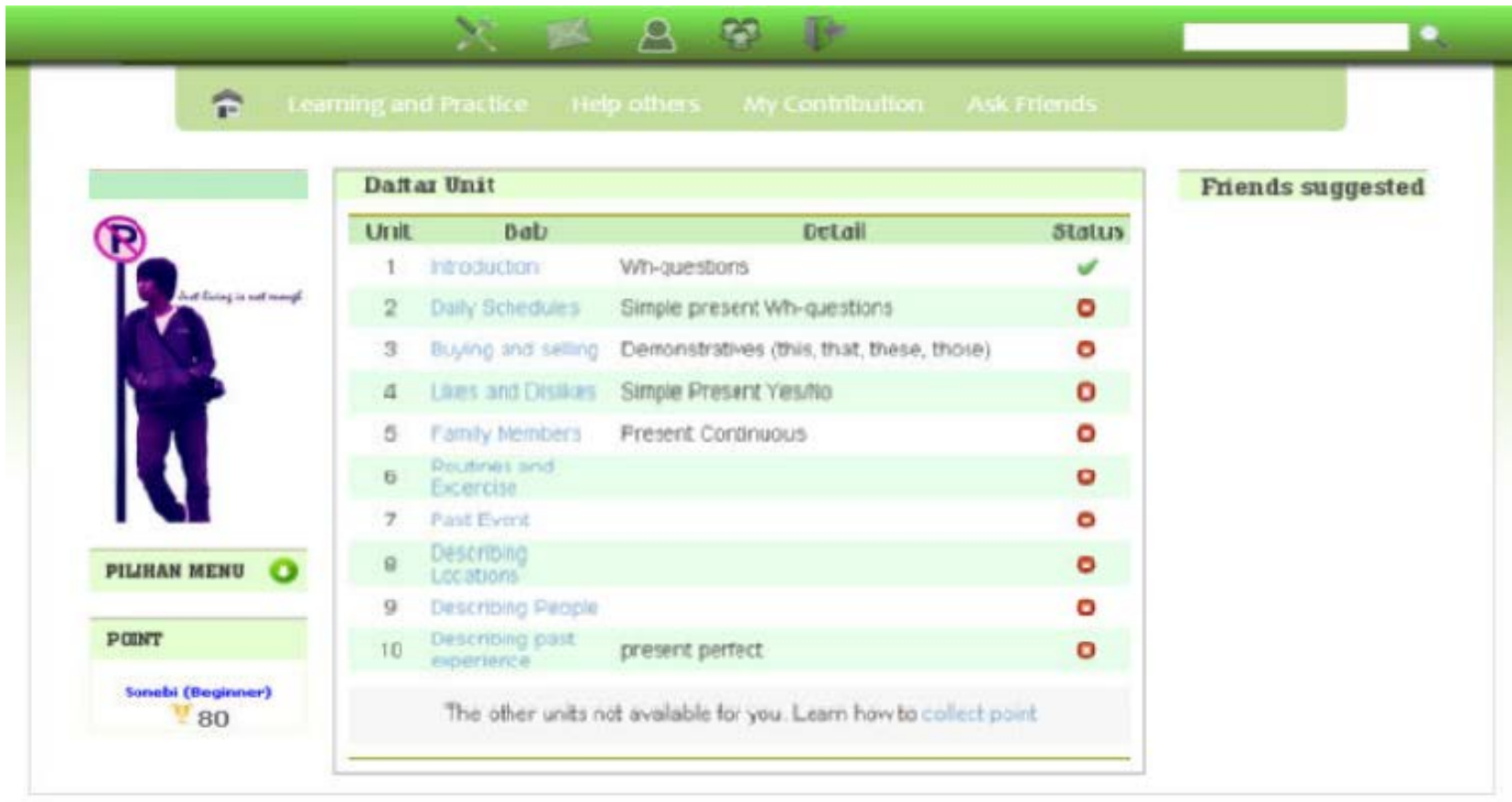

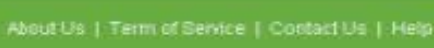

Figure 7. Display Functionality Learning and Practice of Social Networking Application

TABLE 1.

MINIMUM HARDWARE SPECIFICATION

\begin{tabular}{cc}
\hline No & Minimum Hardware Specification \\
\hline CPU Server
\end{tabular}

1. Prosesor 2.13 Ghz L2 Chace 4 MB

2. 4 GB RAM

3. $\quad 80$ GB Hard disk space

CPU Client

1. Intel Pentium 4

2. 256 MB RAM
TABLE 2.

MINUMIM SOFTWARE SPECIFICATION

\begin{tabular}{c}
\hline No $\quad$ Minumim Software Specification \\
\hline CPU Server
\end{tabular}

1. Operating System (Windows, Linux, others)

2. $\quad$ Apache versi 2.2.4

3. PHP 4.0

4. $\quad$ My Sql 2.10 .2

CPU Client

1. Operating System (Windows, Linux, others)

2. Browser supports javascript and HTML5 (Mozilla Firefox, Chrome, others)

TABLE 3.

FUNCTIONALITY TESTING FOR USER REGISTRATION

\begin{tabular}{cllll}
\hline \hline No & \multicolumn{1}{c}{ Input } & Expected Result & \multicolumn{1}{c}{ Result } & Conclusion \\
\hline 1 & Data filled in completely and correctly & Register successfully & Register berhasil & Valid \\
2 & Filled with incorrect data, such as writing the & Failed to Register & Failed to Register & Valid \\
3 & Not filled at all & Failed to Register & Failed to Register & Valid \\
4 & To confirm the password is not the same & Error message & Error message appears & Valid \\
& & & \\
\hline \hline
\end{tabular}

TABLE 4.

TESTING FUNCTIONALITY FOR MANAGING A COMMENT

\begin{tabular}{clllc}
\hline \hline No & \multicolumn{1}{c}{ Input } & Expected Result & \multicolumn{1}{c}{ Result $\mathrm{n}$} & Conclusion \\
\hline 1 & Not Filled & Failed insert & Failed insert & Valid \\
2 & Data filled in correctr & Successfully insert & Successfully insert & Valid \\
3 & Filled more than 200 letters & Failed insert & Failed insert & Valid
\end{tabular}

